\title{
Taking blood from children causes no more than minimal harm
}

\author{
Marjorie Smith Department of Child Psychiatry, Institute of Child Health, Hospital for Sick Children, London
}

\section{Author's abstract}

The ethical question of whether taking blood from normal children for research purposes is justified, is determined in part at least, by whether or not the children are harmed. To try to assess the risks, the effects of venepuncture on a group of healthy subjects were studied, by means of a parental questionnaire completed approximately eighteen months after the venepuncture had taken place. Ninety-two healthy children aged between 6 and 8 had a blood sample taken for non-therapeutic reasons as part of a research study. Questionnaire responses reveal few negative effects, and in some cases positive effects.

It might be argued that children should never be exposed to risk of any harm, either physical or psychological, for the purpose of non-therapeutic research. However, the more common belief within paediatrics is that research is justifiable provided the risk of harm is minimal, and the research will benefit the health or welfare of other children or adults.

The British Paediatric Association (BPA) define risk as 'the risk of causing physical disturbance, discomfort or pain, or psychological disturbance to the child or his parents, rather than the risk of serious harm, which no ethical committee would countenance in any case' (1). They further define negligible risk as 'risk less than that run in everyday life', and minimal risk as 'risk questionably greater than negligible'.

The BPA suggest that procedures involving invasive collection of samples, such as venepuncture to obtain a blood sample, are judged acceptable as long as the risk is no more than minimal, and the research although not necessarily of benefit to the subject, is judged to benefit the health and welfare of other children or adults. However, the Proposed International Guidelines for Biomedical Research involving human subjects (2) imply that the risk is greater than minimal, and that strong justification is always required in research where invasive procedures such as blood sampling are carried out.

Although venepuncture is the most common invasive procedure performed, there is little, if any,

\section{Key words}

Risks of venepuncture; children; non-therapeutic research. systematic information available on the effects of venepuncture, to enable an assessment of the risks? involved, and therefore a judgement of whether the $\vec{F}$ risks are minimal, or more than minimal. The purpose $\dot{\omega}$ of this study was to assess the risks and benefits of $\vec{N}$ blood sampling by venepuncture on a population of healthy children, and in particular to assess whether the risks would be judged to be minimal according to the BPA definition.

It is clear that the effects of venepuncture are not severe or they would have been apparent, but since the consequences have not been systematically investigated, it is not possible to know whether there are any negative, or indeed positive effects of such procedures. In assessing the risks it is also relevant to distinguish the probability of harm from the severity harm. If the risks are small for any individual but the potential harm is great, then this must be balanced against a hazard in which the risk to any individual is greater, but the potential damage is less. The incidence of rare but more serious adverse effects resulting from venepuncture is not known. It is estimated that 2 per cent of adult volunteers suffer minor bruising, while less than 1 in 5,000 suffer more serious harm, such as brushing a superficial nerve, and fewer than 1 in 20,000 suffer more severe damage such as an arterial puncture (Harrison J F: personal communication, 1985). There do not appear to be any published data relating to physical or psychological effects resulting from venepuncture on children.

Rodin (3) carried out a study in which she looked at the effects of preparation on anxiety levels of children $\frac{D}{2}$ before and during blood sampling by venepuncture. The blood samples were obtained as part of a $N$ European Economic Community blood-lead survey from a random sample of 111 healthy children aged $\mathrm{N}$ between 4 and 11 . Rodin adopted an experimental $\omega$ design in which one group of children were provided with specially made preparation games related to the procedure of venepuncture, to play with while waiting. Two further randomly assigned groups were given either games similar in format but unrelated to 0 venepuncture, or nothing, to play with while waiting. $\frac{\mathrm{O}}{\mathbb{D}}$

Children in the first experimental group showed $\stackrel{\odot}{\stackrel{+}{+}}$ less anxiety during venepuncture than children in the $\stackrel{\mathbb{Q}}{\varrho}$ other two groups, although they showed more anxiety 
while waiting, and playing with the games. However, on further analysis it was clear that the increased anxiety was due to the children who had not been told by their parents what was to happen to them, and that children who had been warned showed no greater anxiety while waiting. All children who had been warned by their parents showed less anxiety during the procedure than children who had not been told. One further finding of interest was that children's anxiety while waiting reflected their parents' anxiety, so that the least anxious children were those whose parents were the calmest.

This useful study shows that appropriate preparation, particularly the combined preparation of the parents, and an explanatory and informative game, is effective in reducing the anxiety and stress during a medical procedure such as venepuncture.

Recently an opportunity has arisen to investigate the after-effects and consequences of blood sampling on a similar group of children. The children were part of a sample investigated to study the effects of lead on children (4). The primary measure of lead body burden was shed deciduous teeth, but in order to ascertain the blood-lead range of the population being investigated, and to check the blood/tooth-lead correlations it was felt desirable to obtain blood samples from a small number of children.

The blood samples were taken, and some time later the parents were sent a short questionnaire designed to find out if there had been any noticeable or memorable effect on their child as a result of the procedure.

\section{Methods}

\section{THE SAMPLE}

The parents of 119 children aged between six-and-ahalf to seven-and-a-half, were asked if they would consent to a blood sample being taken from their children. The large majority of these children - 109 were a consecutive sample of children taking part in a lead study (4). A large body of data had been collected on these children, including a measure of IQ, and an estimate of maternal intelligence. The remainder of the sample for this study were children from the same study population, who were not part of the intensively investigated sample. The reason for requesting a blood sample and the procedure for taking the blood was explained to the parents. It was made clear to the parents that there was no reason to suspect that their child's blood lead was outside the normal range, so there was no direct health reason for having the blood taken. One hundred and nine - 92 per cent - of the parents asked consented to the request, and signed written consent forms.

Ethical committee consent to carry out both the lead study, and the blood-sampling procedure, was obtained.

\section{BLOOD-SAMPLING PROCEDURE}

Parents were told we would write to inform them a few days before the blood sample was going to be taken, so they could prepare their child.

The blood samples were taken in schools by a medically qualified person, accompanied by the author. The $2 \mathrm{ml}$ samples were obtained by venepuncture using a sterile disposable syringe, and transferred to a $2 \mathrm{ml}$ collection tube. Before the venepuncture took place, the procedure was explained and the equipment used was shown to the child. The children were asked whether they wanted to look, or close their eyes or look away, and the doctor explained that they would feel a little prick, and this might feel 'funny' but that it would not really hurt. Early experience suggested that some worries, such as the fear that the doctor would put the whole of the needle into the child's arm, or that he would take too much blood, were quite common. This enabled appropriate assurances to be incorporated into the preparation procedures where this was felt to be necessary. The child's consent to proceed was then sought, and if this was given the venepuncture took place, with the author's hand serving as a tourniquet.

It was not possible to arrange a session to take blood from 13 children whose parents had consented. Four children did not consent to venepuncture. In two cases this was a definite and clear verbal refusal of consent, and in the others the child did not dissent verbally, but recoiled and withdrew at the sight of the needle, in one case followed by a request to the doctor to try again.

A total of 92 children provided blood samples. These children were each given a 'Special Award' rosette.

\section{THE QUESTIONNAIRE}

A short questionnaire was sent to parents of children from whom blood samples were obtained. The questionnaire comprised eleven questions concerned with the prospect and procedure of venepuncture, and any changes in the child's attitude or behaviour as a result of the experience. The parents' attitude to the experience was also tapped. As well as questions on the psychological impact of the procedure the questionnaire covered physical after-effects. The questionnaire was in a pre-categorised format, but parents were invited to add descriptions or comments to most questions. All questions, with the exception of the attitude questions, included a 'cannot remember' response category.

The questionnaire was sent out, with a reply-paid envelope tor its return, approximately 18 months after the blood samples had been obtained.

\section{Results}

Seventy-seven - 84 per cent - of the questionnaires were completed. Table 1 shows parents' responses to the questions on the child's reaction before and after the blood sampling. The majority of parents said that their child was not upset at the prospect of a blood sample being taken. Parents' comments in this category ranged from 'excited', to 'did not seem to be 


\section{Table 1: Parents' responses to some of the questions}

We asked you to prepare your child

Was she/he upset at the prospect of a blood sample being taken?

$$
\begin{aligned}
& \text { No } \\
& \text { mildly upset } \\
& \text { moderately upset } \\
& \text { severely upset } \\
& \text { (cannot remember }
\end{aligned}
$$

Was he/she upset after the blood had been taken?

$$
\begin{aligned}
& \text { No } \\
& \text { mildly upset } \\
& \text { moderately upset } \\
& \text { severely upset } \\
& \text { (cannot remember }
\end{aligned}
$$

Did he/she describe the actual blood taking as:

$$
\begin{aligned}
& \text { hurting a lot } \\
& \text { hurting a little } \\
& \text { not hurting at all } \\
& \text { (did not describe } \\
& \text { (cannot remember }
\end{aligned}
$$

Do you think this experience will help if your child needs another blood sample taken, in a hospital, for example?

$$
\begin{aligned}
& \text { Yes } \\
& \text { No } \\
& \text { (don't know }
\end{aligned}
$$

Do you think there were any positive or negative effects on your child when faced with a similar situation - for example visiting the doctor or dentist?

$$
\begin{aligned}
& \text { definitely more worried } \\
& \text { slightly more worried } \\
& \text { none } \\
& \text { slightly more confident } \\
& \text { definitely more confident } \\
& \text { (cannot remember }
\end{aligned}
$$

$\begin{array}{rr}0 & 0 \\ 3 & 4 \\ 42 & 56 \\ 19 & 25 \\ 11 & 15 \\ 2) & \end{array}$

worried at all'. Parents who reported that their children were mildly or moderately upset, commented, 'he was worried you might take too much' and 'just a little bit upset because she didn't know what it would be like'.

Similarly most of the parents said their child was not upset after venepuncture. No child was reported to have been upset for more than a day, or more than mildly upset.

Nearly all children - 97 per cent - described the experience to their mother or family. Most reported that it hurt only a little or did not hurt at all. The mother of one of the two children who said that it hurt a lot commented 'She is a bit of a hypochondriac so I did not take much notice. She makes enough fuss over having a plaster on'.

In terms of physical after-effects six children were reported as having bruising and five a sore arm. No N other physical after-effects were reported.

Table 1 also shows parents' responses to questions on changes in the child's attitude, and the parents $\stackrel{0}{ᄃ}$ feelings about the experience. Most parents felt the experience would help if a blood sample was required in the future, although some did not (or thought that it would make no difference). The majority of respondents also felt their child's attitude to similar? situations like visiting the doctor or dentist was $\varrho$ unchanged, or they were more confident. One parent 
commented that her child was now more confident that if the dentist had to give her an injection it would not hurt as much as she had thought. Three parents felt that the venepuncture had resulted in their child being slightly more worried in similar situations. One of these mothers said her daughter, who was frightened of needles after an earlier bad experience in a hospital, had, since the venepuncture, expressed concern when going to the doctor in case she had to have an injection.

Most parents felt there had been no overall change as a result of the experience, but 16 parents felt the effects were slightly positive, and ten parents felt the effects were definitely positive. No parent thought the general effects were negative in any way. The majority of parents $-\mathrm{N}=69,90$ per cent - said they would make the same decision again, to agree to non-theraputic blood sampling from their child. Three parents said they would not, and five parents were undecided.

There were no sex or social group differences in the reactions to the experience of venepuncture. Children who were reported to be mildly or moderately upset at the prospect of a blood sample being taken were more likely to be mildly upset afterwards $(\mathrm{p}<.01)$ and perhaps not surprisingly somewhat less likely to report that it did not hurt at all. There was a significant link $(\mathrm{p}<.05)$ between reporting physical after-effects such as bruising or a sore arm, and being mildly upset after the venepuncture.

For the 71 children for whom IQ measures and estimates of maternal intelligence were available, it was possible to look for IQ differences in the reaction to, or perception of, this experience. Analysis of variance revealed no significant differences in relation to the child's intelligence, but mothers who reported their children as having gained confidence in facing similar situations were more intelligent, on average, than mothers who reported no change, or thought their children were more worried $(\mathrm{p}<.01)$. Similarly, mothers who thought the general effects on their child were positive, scored higher on average on the IQ test than mothers who reported no change $(\mathrm{p}<.05)$.

\section{Discussion}

The questionnaire was not sent out until some 18 months after the blood samples had been taken. This is rather a long gap for parents to remember the effects of venepuncture, but has the advantage that delayed effects, for example on visiting the doctor, would be picked up. Although most questions on the questionnaire had a category for parents who could not remember the events, few parents used this category, and most at least appeared to remember the event in some detail, so there is no reason to suggest that the response would have been different had the questionnaire been sent out soon after the event. There is no reason to suggest that the picture would have altered significantly if the response rate had been higher. A postal strike in an area where several of the children lived complicated the survey, but ten parents who had not replied to the postal reminder were visited, and asked to complete the questionnaire. Their responses were not noticeably different from those who had replied by post.

In general the results confirm the impression gained by the author and the doctor performing the venepuncture, that in most cases the experience produced trivial upset or no upset at all, and that it could sometimes have positive effects. There is no doubt that most children felt some anxiety, if only slight, before the experience of venepuncture. However, the anxiety in this situation was probably less than in many situations in which venepuncture takes place. The parents were, at our request, specifically asked to prepare the child, and this is something which Rodin showed was an important factor in reducing anxiety (3). The venepuncture was carried out in school on familiar territory (and in addition the child was singled out for a special event) and it was unconnected with any traumatic event such as an injury or illness, and these factors probably reduced upset.

Some children nevertheless did find it an upsetting experience, although the upset lasted for only a day. The indications from this study are that children who were upset at the prospect of venepuncture were the ones who were upset afterwards. This appears to indicate that it is the personality characteristics of the children that ultimately determine their response to this sort of experience. It also suggests that in seeking parental consent the parent should be questioned about the child's behaviour. This would enable children who were unusually anxious or fearful of new situations, or who had experience of, and were already frightened of such procedures, to be excluded.

The results of this study indicate that for many children the successful negotiation of this anxietyinducing experience gave the child a positive sense of achievement and pride. Parents commented ' $\mathrm{He}$ came back bursting with pride and talked of little else for days. The rosette is still one of his most prized possessions'. Another parent commented 'She felt proud and a little bit more grown up'. In our view this study vindicates the BPA working party view that the 'risk' of venepuncture is minimal in non-theraputic research, provided that unusually anxious or unwilling children are excluded.

\section{Acknowledgements}

This study was carried out while the author was supported by a grant from the Economic and Social Research Council.

All the blood samples were taken by Dr Wasyl Nimenko, and his help is gratefully acknowledged.

Marjorie Smith is a Lecturer and Research Psychologist in The Department of Child Psychiatry, Institute of Child Health, the Hospital for Sick Children, Great Ormond Street, London WCIN $37 H$. 


\section{References}

(1) British Paediatric Association Working Party. Guidelines to aid ethical committees considering research involving children. Archives of disease in childhood 1980; 55: 75-77.

(2) Council for International Organisations of Medical Sciences. Proposed international guidelines for biomedical

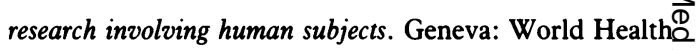
Organisation, Council for International Organisations ofm Medical Sciences, 1982.

(3) Rodin J. Will this hurt? London: Royal College of Nursingê? Research Monograph, 1983.

(4) Smith M,Delves T, Lansdown R, Clavton B and Graham P. The effects of lead exposure on urban children: the Institute $\bar{O}$ of Child Health/Southampton study. Supplement 47 too Developmental medicine and child neurology.

\section{Update}

\section{Medical ethics courses}

More than 200 people have already expressed interest in a new MA in the Philosophy of Health Care course which is to begin in October at the University of Wales. Applications have come from a wide variety of people, says Dr Donald Evans of the Department of Philosophy, 'from hospital consultants, pharmacists, administrators, psychiatrists and senior nursing staff - just the sort of spread we were hoping for'.

The course, which consists of a two-year scheme of part-time study, aims to provide practitioners and administrators in medicine and health care with the opportunity to examine the ethical and philosophical problems encountered in their disciplines.

Candidates will normally be graduates who are either medical doctors, clinical psychologists, paramedical staff (pharmacists, radiologists etc), hospital or health service administrators, medical social workers, medical researchers, senior nurses or lay members of health authorities.

The course will be taught by members of the Philosophy Department of University College, Cardiff with the co-operation of visiting experts who will include: Baroness Mary Warnock, Professor Alan Maynard of the University of York and Dr Raanan Gillon, editor of the fournal of
Medical Ethics. The curriculum will cover: Philosophy, morality and health care; Administration of health care; The doctor-patient relationship; Patient perspectives; Reproductive medicine; Medical and scientific research; Death and treatment of the dying; Health and disease; Drugs, and Mental illness.

The fee is $£ 411$ per year and anyone interested in learning more about the course should contact: $\mathrm{Dr}$ Donald Evans, PO Box 78, Cardiff CF1 1XL.

- The Centre of Medical Law and Ethics at King's College, London established a Postgraduate Diploma course in Medical Ethics and Law in 1984. The course lasts for a year and is open to graduates in medicine, philosophy, law or any other relevante disciplines. To obtain the diploma, awarded by King's College, candidates must pass an examination in June and complete a 12,000 word (approximately) thesis by September. The course is aimed principally, but not exclusively, at those who are already professionally involved in ethical and legal issues arising out of the practice of medicine.

The aim of the course is to expose an increasing number of professionals to a rigorous and stimulating discipline which will equip them to meet the growing demand for expertise in the area and to help to train others, whether nurses, medical students, administrators, hospital chaplains, etc.

Further information may be obtained from The Secretary, Centre of Medical Law and Ethics, King's College, London WC2. 